\title{
Determination of heavy metals in indoor dust from primary school (Sri Serdang, Malaysia): estimation of the health risks
}

\begin{abstract}
Heavy metal concentrations $(\mathrm{Pb}, \mathrm{Cd}$, and $\mathrm{Cu})$ in classroom indoor dust were measured. The health risk (non-carcinogenic) of these heavy metals in classroom indoor dust to children was assessed based on United States Environmental Protection Agency health risk model. Indoor classroom dust samples were collected from 21 locations including windows, fans, and floors at a primary school in Sri Serdang, Malaysia. Classroom dust samples were processed using aqua regia method and analyzed for $\mathrm{Pb}, \mathrm{Cd}$, and $\mathrm{Cu}$ concentrations. The highest average heavy metal concentrations were found in windows, followed by floor and fan. $\mathrm{Pb}$ concentrations ranged from $34.17 \mathrm{\varepsilon g} / \mathrm{g}$ to $101.87 \mathrm{\varepsilon g} / \mathrm{g}$, Cd concentrations ranged from 1.73 $\varepsilon \mathrm{g} / \mathrm{g}$ to $7.5 \mathrm{\varepsilon g} / \mathrm{g}$, and $\mathrm{Cu}$ concentrations ranged from $20.27 \mathrm{\varepsilon g} / \mathrm{g}$ to $82.13 \mathrm{\varepsilon g} / \mathrm{g}$. Ventilation and cleaning process were found as the possible factors that contributed to heavy metal concentration in window, floor, and fan. Moreover, the hazard index (HI) and hazard quotient (HQ) values for heavy metals $\mathrm{Cd}$ and $\mathrm{Cu}$ were less than one. By contrast, the $\mathrm{HI}$ and $\mathrm{HQ}$ values for $\mathrm{Pb}$ (maximum values) were more than one, indicating potential non-carcinogenic risk to children. Long-term persistence of leaded petrol, building materials, interior paint, school located near industrial areas and major roads, as well as vehicle emission are the factors attributed to the presence of heavy metals in classroom dust. Further research under a long-term monitoring plan and actual values in a health risk model is crucial before a final decision on heavy metal exposure and its relationship to young children health risks can be made. Nevertheless, the findings of this study provide crucial evidence to include indoor dust quality in school assessment because the environmental processes and impacts of surrounding school area have health risk implications on young children.
\end{abstract}

Keyword: Heavy metals; Indoor dust; Children; Health risk 